\title{
Kinetics of G-phase precipitation and spinodal decomposition in very long aged ferrite of a Mo-free duplex stainless steel
}

\author{
C. Pareige ${ }^{a, *}$, J. Emo a , S. Saillet ${ }^{\text {b }}$, C. Domain ${ }^{\text {b }}$, P. Pareige ${ }^{\text {a }}$ \\ ${ }^{a}$ Groupe de Physique des Matériaux, UMR 6634 CNRS, Université et INSA de Rouen, Avenue de l'Université, BP 12, 76801 Saint Etienne du Rouvray, France \\ ${ }^{\mathrm{b}}$ EDF R\&D Département Matériaux et Mécanique des Composants, Avenue des Renardières - Ecuelles, F-77250 Moret sur Loing, France
}

Keywords:

Duplex stainless steels Atom probe tomography Phase transformations Spinodal decomposition G-phase precipitation

\begin{abstract}
A B S T R A C T
Evolution of spinodal decomposition and G-phase precipitation in ferrite of a thermally aged Mo-free duplex stainless steel was studied by Atom Probe Tomography (APT). Kinetics was compared to kinetics observed in ferrite of some Mo-bearing steels aged in similar conditions. This paper shows that formation of the G-phase particles proceeds via at least a two-step mechanism: enrichment of $\alpha / \alpha^{\prime}$ interdomains by G-former elements followed by formation of G-phase particles. As expected, G-phase precipitation is much less intense in the Mo-free steel than in Mo-bearing steels. The kinetic synergy observed in Mo-bearing steels between spinodal decomposition and G-phase precipitation is shown to also exist in Mo-free steel. Spinodal decomposition is less developed in the ferrite of the Mo-free steel investigated than in Mo-bearing steels: both the amplitude of the decomposition and the effective time exponent of the wavelength (0.06 versus 0.16$)$ are much lower for the Mo-free steel. Neither the temperature of homogenisation nor quench effects or $\mathrm{Ni}$ and Mo contents could successfully explain the low time exponent of the spinodal decomposition observed in the Mo-free steel. The diffusion mechanisms could be at the origin of the different time exponents (diffusion along $\alpha / \alpha^{\prime}$ interfaces or diffusion of small clusters).
\end{abstract}

\section{Introduction}

Duplex stainless steels (DSS) are used in the primary circuit of pressurized water reactor (PWR). These materials are prone to thermal ageing at the service temperature, typically between $285^{\circ} \mathrm{C}$ and $323^{\circ} \mathrm{C}[1,2]$. This ageing is due to ferrite decomposition which leads to a decrease in Charpy toughness and an increase in Vickers hardness [2,3]. Numerous studies have shown that the evolution of the mechanical properties depends on the DSS composition [3-6]. Mo-free grades which also contain a smaller amount of nickel than Mo-bearing ones were shown to age less [3-5]. Spinodal decomposition (development of Fe rich $\alpha$ zones and $\mathrm{Cr}$ rich $\alpha^{\prime}$ zones) of the ferrite and to a lesser extent formation of Gphase particles are recognized as the primary mechanisms of ageing of DSS.

$\mathrm{G}$-phase particles form at the interface between $\alpha$ and $\alpha^{\prime}$ regions thereby demonstrating that $\alpha-\alpha^{\prime}$ decomposition and G-phase precipitation are highly dependent $[2,5,7]$. Investigation of phase

\footnotetext{
* Corresponding author.

E-mail address: cristelle.pareige@univ-rouen.fr (C. Pareige).
}

separation of the ferrite of Mo-bearing steels [7,8] revealed kinetics synergy between $\mathrm{G}$-phase precipitation and spinodal decomposition. The intensity of G-phase precipitation is much higher in Mobearing DSS than in Mo-free steels (with less G-forming elements) [7,9]. From the numerous studies of phase transformation in these steels $[1,5-7,9,10]$, it has been suggested that G-phase precipitation results from the rejection of $\mathrm{Si}$ from $\alpha$ domains and $\mathrm{Ni}$ from $\alpha^{\prime}$ domains $[5,10,11]$. The cross flow of these species towards the interfaces helps the nucleation of G-phase particles. Mateo et al. [10] proposed a two-step formation mechanism of G-phase precipitates: i) fluxes of G-forming species induced by their rejection from $\alpha$ and $\alpha^{\prime}$ domains lead to enrichment at the $\alpha / \alpha^{\prime}$ inter-domains of G-forming elements ( $\mathrm{Si}, \mathrm{Ni}, \mathrm{Mn}$ and $\mathrm{Mo}$ ), ii) when the composition of the inter-domains reaches a critical composition, G-phase particles could form.

Spinodal decomposition was also shown to develop more strongly in Mo-bearing steels [7]. Although the respective contributions of Ni and Mo are difficult to differentiate, the contribution of Ni seems more pronounced according to the literature $[6,7,12]$. Brown et al. [13] highlighted enhancement of spinodal decomposition in $\mathrm{Fe}-\mathrm{Cr}-\mathrm{Ni}$ alloys with increasing $\mathrm{Ni}$ content. However, 
none of the previous studies in the literature undertook a study on the kinetics of phase separation in Mo-free steels for very long ageing times. Comparisons were only done sporadically for one or two ageing times.

This paper aims at describing the kinetics of spinodal decomposition and G-phase precipitation in a Mo-free steel aged at $350{ }^{\circ} \mathrm{C}$ up to $100,000 \mathrm{~h}$ by atom probe tomography (APT). To our knowledge, this work presents the first study of the kinetics of phase separation in Mo-free DSS at the nanoscale. After presentation of the materials and the experimental technique, we give, owing to the investigation of the onset of phase separation, the experimental evidence that spinodal decomposition appears before G-phase precipitates and that $\mathrm{G}$-phase precipitate formation proceeds at least in two steps as firstly suggested by Mateo et al. [10]. In the last part of the article, the results obtained on the Mo-free grade and previous results obtained on Mo-bearing grades aged in similar conditions $[14,15]$ are compared to highlight the kinetics differences and commonalities between the two grade families. The possible origins of the differences are also discussed.

\section{Materials and experimental techniques}

\subsection{Materials}

The duplex stainless steel studied in the present work is a Mofree steel provided by Electricité de France (EDF). This Mo-free DSS, labelled $\mathrm{E}$ in the paper, was laboratory aged at $350{ }^{\circ} \mathrm{C}$ from 2500 to $100,000 \mathrm{~h}$. It contains $12 \%$ of ferrite and its composition is given in Table 1. The kinetic of phase transformation in the ferrite of the steel $\mathrm{E}$ will be compared with Mo-bearing steels analysed by Pareige et al. [14] and Novy [15]. The compositions of the latter steels are also given in Table 1 together with the homogenization temperature, the volume fraction of ferrite, the ageing temperature and the intervals of ageing time. As reported in Table 1, Mo-bearing steels were aged at different temperatures. In order to compare the different kinetics, time-temperature equivalence was applied. Considering that the evolution of the microstructure is thermally activated, it is reasonable to write the evolution of the different parameters as an Arrhenius law over the studied range of decomposition. Such an assumption was demonstrated to be valid for the Mo-bearing steels in Table 1 by Pareige et al. [14] and Novy [15] in the temperature range $300^{\circ} \mathrm{C}-350^{\circ} \mathrm{C}$. The equivalent ageing time at $323{ }^{\circ} \mathrm{C}\left(\mathrm{t}_{\mathrm{eq}} 323^{\circ} \mathrm{C}\right)$ is deduced from the ageing time at temperature $\mathrm{T}\left(\mathrm{t}_{\mathrm{T}}\right)$ owing to the following relationship:

$\mathrm{t}_{\text {eq } 323{ }^{\circ} \mathrm{C}}=\mathrm{t}_{\mathrm{T}} \exp \left[\frac{\mathrm{Q}}{\mathrm{R}}\left(\frac{1}{596}-\frac{1}{\mathrm{~T}}\right)\right]$

where: $\mathrm{R}$ is the gas constant, $\mathrm{T}$ is the ageing temperature $(\mathrm{K}), \mathrm{Q}$ is the activation energy governing the spinodal decomposition in the temperature range [ $323{ }^{\circ} \mathrm{C}-\mathrm{T}$ ]. The value of $\mathrm{Q}$ is $243 \mathrm{~kJ} / \mathrm{mol}$ in the range $\left[323{ }^{\circ} \mathrm{C}-350{ }^{\circ} \mathrm{C}\right][7,14,16,17]$ and $104 \mathrm{~kJ} / \mathrm{mol}$ in the range $\left.\left[300{ }^{\circ} \mathrm{C}-323^{\circ} \mathrm{C}\right]\right)$. The latter activation energy was calculated by comparing the value of the wavelength obtained in the ferrite of the steel D aged at $300{ }^{\circ} \mathrm{C}$ with the values obtained in the other Mobearing steels in Table 1 . The low value of the activation energy could suggest a change in mechanism at $300^{\circ} \mathrm{C}$. As we do not have any other data at this temperature, it is not possible to discuss this point. The same activation energy $(\mathrm{Q}=243 \mathrm{~kJ} / \mathrm{mol})$ was used to calculate the equivalent ageing time for the Mo-free steel. Indeed, Brown and Smith [13] who studied the spinodal decomposition rate in model $\mathrm{Fe}-\mathrm{Cr}-\mathrm{Ni}$ alloys, showed that the Ni content does not affect the value of the activation energy but rather the preexponential term. Moreover, our goal was not to estimate the activation energy which leads to the same ageing in Mo-free and Mo-bearing steels but rather to study the kinetics differences between Mo-bearing and Mo-free steels. Consequently, it is important to conserve the differences observed at $350^{\circ} \mathrm{C}$ between steel $\mathrm{E}$ and steels $\mathrm{A}$ and $\mathrm{B}$ that were also aged at $350^{\circ} \mathrm{C}$ (Table 1 ) even after time rescaling at $323^{\circ} \mathrm{C}$.

\subsection{Experimental techniques}

The ferrite of steel E was investigated with an energy compensated wide angle tomographic atom probe (ECoWATAP) combined with an advanced delay line position-sensitive detector (aDLD) which minimizes the loss of information due to impact superposition or multi-event detection [18]. The energy compensating lens provides a high mass resolution and improves the accuracy of composition measurements [19]. During the experiment, the specimens were cooled down to $45 \mathrm{~K}$ in order to mitigate preferential field evaporation processes. Atoms were evaporated by applying an electric pulse of $20 \%$ of the DC voltage with a pulse repetition rate of $30 \mathrm{kHz}$. For further information about this technique, the reader is referred to [20-22]. APT samples were prepared by both focus ion beam (FIB) and standard electro polishing methods. 3D reconstructions and data processing were performed using the 3D Data Software for Atom Probe users developed by the GPM research group in Rouen, France (see authors affiliation). The mean wavelength of the spinodal decomposition $\left(\lambda_{\alpha^{\prime}}\right)$ was estimated using autocorrelation functions calculated from 1D $\mathrm{Cr}$ concentration profiles [23]. The profiles were drawn by extracting volumes of square cross section of $1 \times 1 \mathrm{~nm}^{2}$ from the whole analysed volume and by moving a $1 \times 1 \times 1 \mathrm{~nm}^{3}$ box along the $z$ axis with a step value of $0.1 \mathrm{~nm}$. At least five values of the wavelength were derived from each autocorrelation profile and several profiles were calculated per analysed volume. The uncertainty on the wavelengths was taken equal to two times the standard deviation calculated on the whole set of measured wavelengths for a given ageing time.

Table 1

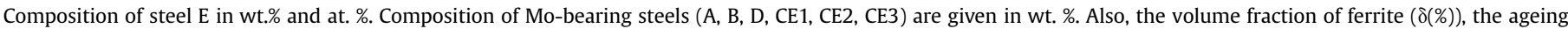
temperature, intervals of ageing time and homogenization temperature are given.

\begin{tabular}{|c|c|c|c|c|c|c|c|c|c|c|c|}
\hline Steel & $\mathrm{Cr}$ & Si & $\mathrm{Ni}$ & Mo & Mn & C & Fe & $\delta(\%)$ & $\mathrm{T}_{\mathrm{V}}\left({ }^{\circ} \mathrm{C}\right)$ & Ageing time intervals $(\mathrm{h})$ & $\begin{array}{l}\text { Homogenization } \\
\text { temperature }\left({ }^{\circ} \mathrm{C}\right)\end{array}$ \\
\hline $\mathrm{E}(\mathrm{wt} \%)$ & 20.30 & 0.95 & 8.40 & 0.04 & 0.84 & 0.03 & Bal. & 12 & 350 & $2500-100,000$ & 1080 \\
\hline E (at \%) & 21.35 & 1.85 & 7.82 & 0.02 & 0.84 & 0.14 & Bal. & 12 & 350 & $2500-100,000$ & 1080 \\
\hline A (wt \%) & 21.02 & 1.12 & 9.81 & 2.60 & 0.66 & 0.03 & Bal. & 29.5 & 350 & $2500-72,000$ & 1120 \\
\hline B (wt \%) & 20.08 & 1.12 & 11.68 & 2.49 & 0.81 & 0.03 & Bal. & 17 & 350 & $100,000-200,000$ & 1080 \\
\hline $\mathrm{D}(\mathrm{wt} \%)$ & 20.78 & 1.03 & 11.68 & 2.56 & 0.57 & 0.04 & Bal. & 21 & 300 & $90,000-200,000$ & 1080 \\
\hline CE1 (wt \%) & 21.02 & 1.12 & 9.81 & 2.60 & 0.66 & 0.03 & Bal. & 29.5 & 325 & 163,219 & 1120 \\
\hline CE2 (wt \%) & 20.45 & 0.94 & 10.32 & 2.63 & 0.85 & 0.03 & Bal. & 23 & $323+350^{a}$ & $103,635+60,000$ & 1130 \\
\hline CE3 (wt \%) & 20.51 & 1.16 & 10.41 & 2.58 & 0.49 & 0.03 & Bal. & 23 & $323+350^{a}$ & $103,635+60,000$ & 1080 \\
\hline
\end{tabular}

${ }^{\text {a }}$ In-service ageing at $323{ }^{\circ} \mathrm{C}$ for $103,635 \mathrm{~h}$ followed by a further lab ageing at $350{ }^{\circ} \mathrm{C}$ for $60,000 \mathrm{~h}$. 
Measurement of the composition of $\alpha$ (Fe-rich) and $\alpha^{\prime}$ (Cr-rich) zones was performed using the method based on the radial distribution function analysis (RDF) proposed by Zhou et al. [24]. As explained by the authors, this method limits the effect of the choice of composition thresholds employed to isolate $\alpha$ and $\alpha^{\prime}$ zones. Moreover, it has the advantage to propose a standardised method for characterizing spinodal decomposition enabling pertinent comparison between the various works produced within the APT community. In the following, the evolution of the $\mathrm{Cr}$ concentration field during spinodal decomposition is characterised by the $\mathrm{Cr}$ concentration amplitude of decomposition $\Delta \mathrm{C}_{\mathrm{Cr}}=\mathrm{C}_{\alpha^{\prime}}-\mathrm{C}_{\alpha}$ where $\mathrm{C}_{\alpha^{\prime}}$ and $\mathrm{C}_{\alpha}$ are the $\mathrm{Cr}$ concentration in $\alpha$ and $\alpha^{\prime}$ zones respectively as calculated with the method proposed by Zhou et al. [24].

To distinguish G-phase particles from $\alpha$ and $\alpha^{\prime}$ zones, a filter in composition called "iso-position" [25] was applied using the concentration threshold $\mathrm{X}_{\mathrm{Ni}+\mathrm{Si}}>15 \%$ for the ageing time of $2500 \mathrm{~h}$ and $\mathrm{X}_{\mathrm{Ni}+\mathrm{Si}}>20 \%$ for the longer ageing times $(\geq 10,000 \mathrm{~h})$. These thresholds ensure that all the G-phase particles are detected and that no ghost G-phase particles are selected. Fe shells are sometimes observed around particles. These shells were removed using an erosion method. Once the Fe shells were removed, the radius of each individual particle was deduced from its number of atoms (n) $\left(R=\sqrt[3]{3 n V_{a t} / 4 \pi Q}\right.$ where $\mathrm{Q}=0.5$ is the detector efficiency; $V_{a t}=a^{3}$ ) 2 is the atomic volume with $a=0.286 \mathrm{~nm}$ the lattice parameter of the ferrite). The number density of the G-phase particles was determined by a simple ratio of the number of the observed precipitates to the overall analysed volume. The volume fraction was defined as the ratio of the number of atoms inside the precipitates to the total number of collected atoms. Three different methods were used to measure the in-core composition of the G-phase particles: i) measurements performed in the core of each cluster by placing a small box inside, ii) erosion profiles and iii) radial profiles. For ii) and iii) methods, in-core composition was obtained by only considering the atoms belonging to the plateau of the composition profile. In all cases, isobaric overlaps were corrected. Compositions obtained by these three methods were shown to be very similar [26].

\section{Results and discussion}

\subsection{Phase transformation in the ferrite of the steel E (Mo-free steel)}

3D reconstructions of the ferrite of E DSS at each ageing time are presented in Fig. 1. As expected, a well-developed interconnected structure of $\mathrm{Cr}$ atoms associated with $\alpha / \alpha^{\prime}$ spinodal decomposition is revealed. After $10,000 \mathrm{~h}$ of ageing, well-defined $\mathrm{G}$ phase precipitates at the $\alpha / \alpha^{\prime}$ interface are observed. This precipitation of Gphase in Mo-free DSS has been reported by several authors [1,6,9]. The microstructural evolution of the ferrite in the $\mathrm{E}$ steel is qualitatively similar to the one observed by Pareige et al. in Mo-bearing steels at the same temperature and the same range of ageing time [14].

Conversely, after $2500 \mathrm{~h}$ of ageing, the G-phase particles are not well defined. Many of them spread over the $\alpha / \alpha^{\prime}$ interface, others are already spherical (Fig. 1). Their number density and their size are very sensitive to the value of the threshold used to distinguish them from $\alpha$ and $\alpha^{\prime}$ zones. It is the beginning of the precipitation of the G-phase.

The time evolution of the decomposition amplitude for $\alpha / \alpha^{\prime}$ decomposition is given in Fig. 2. No plateau is observed even after $100,000 \mathrm{~h}$ of ageing at $350^{\circ} \mathrm{C}$. Composition measurements of $\alpha$ and $\alpha^{\prime}$ zones show that the $\mathrm{Cr}$ concentration still evolves in both $\alpha$ and $\alpha^{\prime}$ zones after $100,000 \mathrm{~h}$ of ageing [26].

The evolution of $\lambda_{\alpha^{\prime}}$ as function of the equivalent ageing time at $323{ }^{\circ} \mathrm{C}$ is presented in Fig. 3. A power law $\mathrm{At}^{\mathrm{n}}$ is observed with
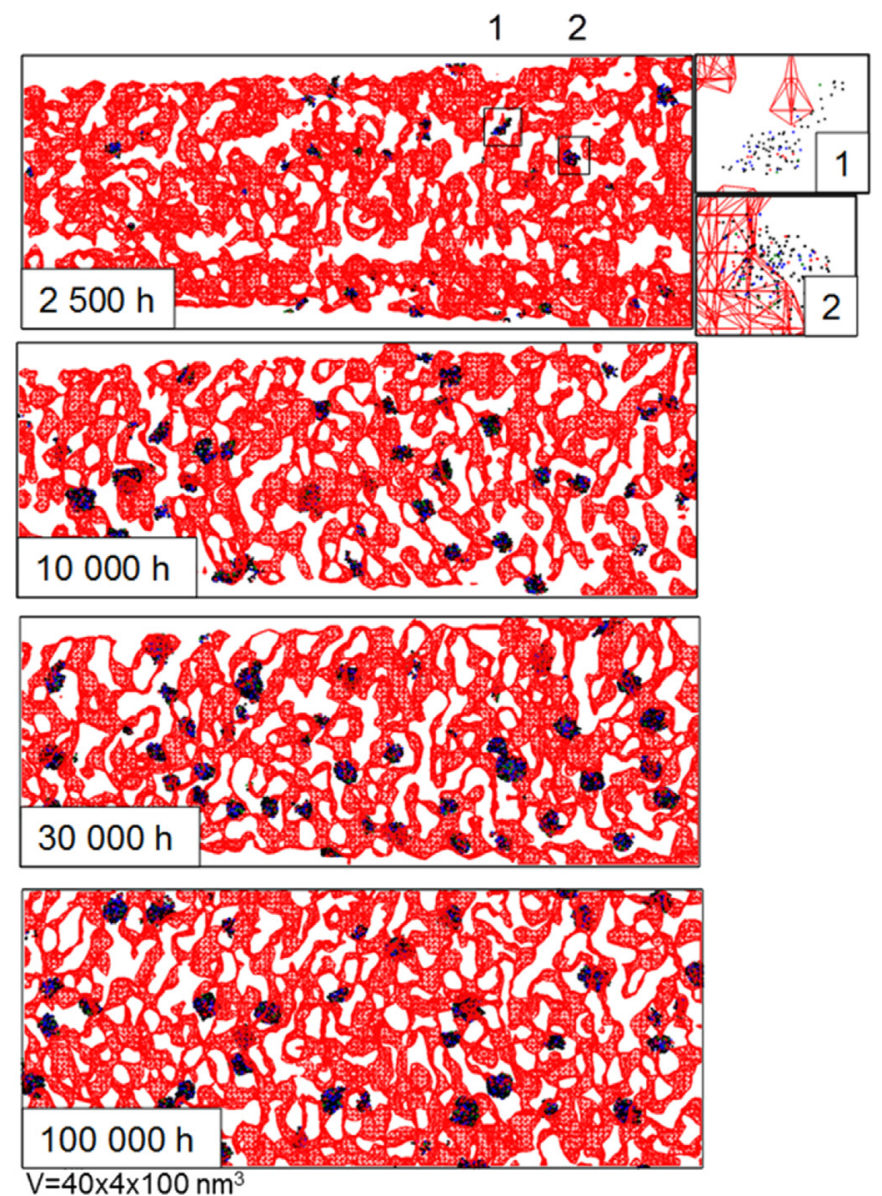

Fig. 1. Atom probe tomography reconstructions of the ferrite of $E$ steel. Red lines represent iso-surfaces obtained with $\mathrm{X}_{\mathrm{Cr}}>25 \%$ threshold. Black dots represent $\mathrm{G}$ phase particles; $\mathrm{X}_{\mathrm{Si}+\mathrm{Ni}}>15 \%$ threshold was used. (The volume represented is a $4 \mathrm{~nm}$ slice of $40 \mathrm{~nm} \times 100 \mathrm{~nm}$ ). (For interpretation of the references to colour in this figure legend, the reader is referred to the web version of this article.)

$\mathrm{n}=0.07$ which is a very low value with respect to both classical exponents for spinodal decomposition $(0.16-0.18[27,28])$ and values observed for Mo-bearing steels (Fig. 3 and $[7,14]$ ). To our

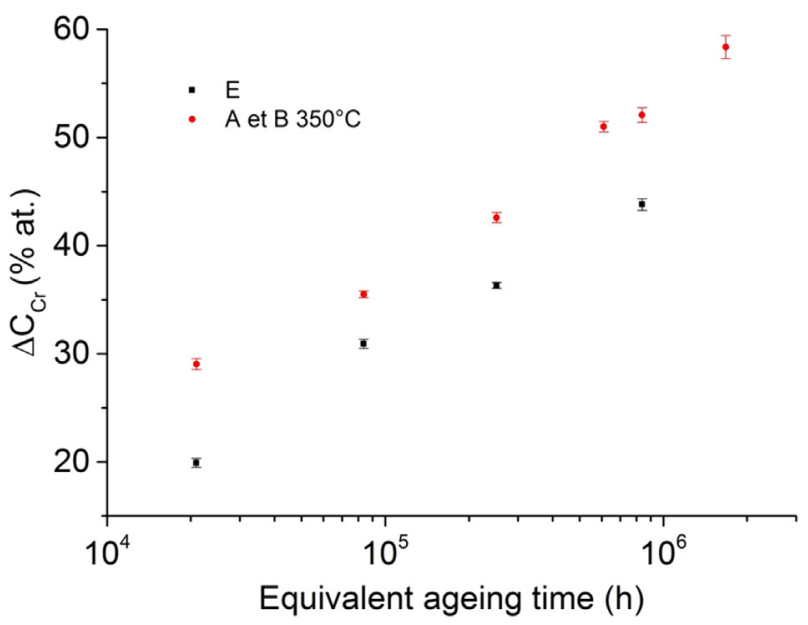

Fig. 2. Amplitude of $\mathrm{Cr}$ concentration during $\alpha / \alpha^{\prime}$ decomposition in ferrite of steel $\mathrm{E}$ (black squares) and in A and B Mo-bearing steels (red circles) as function of the equivalent ageing time at $323^{\circ} \mathrm{C}$. A, B and E were aged at $350{ }^{\circ} \mathrm{C}$. (For interpretation of the references to colour in this figure legend, the reader is referred to the web version of this article.) 


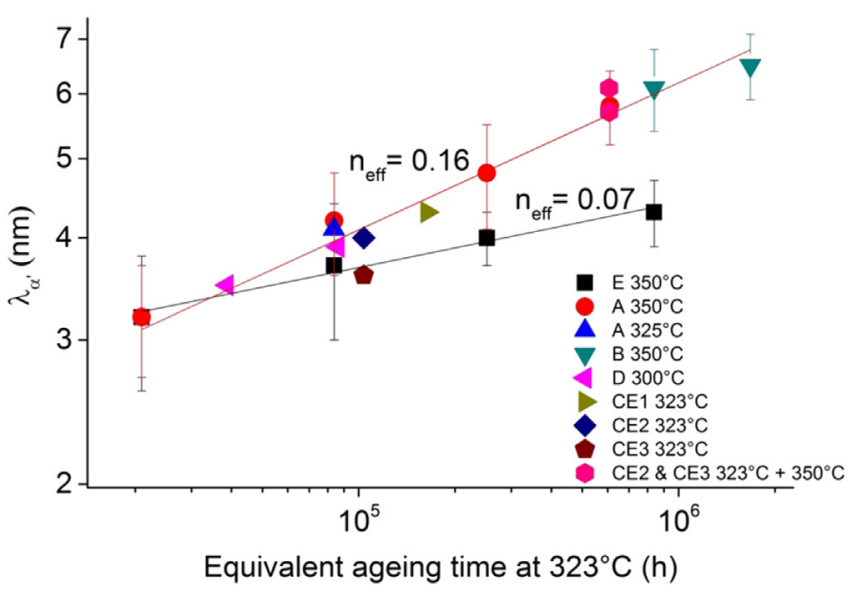

Fig. 3. Time evolution of the mean wavelength of the spinodal decomposition in the ferrite of steel E (black squares) and in Mo-bearing steels A, B, D, CE1-CE3 of Table 1.

knowledge, it is the first time that a so small exponent is reported for the evolution of the wavelength of spinodal decomposition in ferrite of DSS but it is also the first time that kinetics of spinodal decomposition is studied in Mo-free steel. Low values (between 0.078 and 0.097) were reported by Hamaoka et al. [29] in a Mobearing steel aged at different temperatures. Nevertheless, the authors did not evaluate the evolution of the wavelength but instead the evolution of the width of the $\alpha^{\prime}$ rich zones. These low time exponents agree well with the time exponent of the width of the spinodal decomposition measured by Pareige at al [14]. in steels A and B. In DSS steels, all the characteristic lengths do not behave with the same time exponent. In $\mathrm{Fe}-\mathrm{Cr}$ alloys, the smallest value measured for the wavelength was 0.12 in a $\mathrm{Fe}-32 \% \mathrm{Cr}$ by Lasalle and Schwartz [30]. It is not possible at this stage to know if this behaviour is representative of all Mo-free steels or only of the steel E. Further investigation of other Mo-free steels is needed to conclude on this point.

The composition of the G-phase particles at the different ageing times is reported in Table 2. Time evolution of the radius, number density and volume fraction of G-phase particles are presented in Fig. 4. Both a significant enrichment in G-former elements and an increase in radius of $\mathrm{G}$-phase particles are observed between 2 $500 \mathrm{~h}$ and $10,000 \mathrm{~h}$ of ageing at $350{ }^{\circ} \mathrm{C}$. As already mentioned above, this gives a strong indication of the fact that G-phase precipitation is only at an early stage at $2,500 \mathrm{~h}$ of ageing whereas spinodal decomposition is already well developed. These observations confirm that phase transformation in ferrite starts firstly by $\alpha / \alpha^{\prime}$ spinodal decomposition and that G-phase precipitate formation at $\alpha / \alpha^{\prime}$ interface results from the rejection of G-forming species from $\alpha$ and $\alpha^{\prime}$ domains as firstly suggested by Chung and Leax [5] and Danoix et al. [11]. But more importantly, these results also

Table 2

Composition (at.\%) of G-phase particles in steel E aged at $350{ }^{\circ} \mathrm{C}$ between $2500 \mathrm{~h}$ and $100,000 \mathrm{~h}$ (between $2 \times 10^{4} \mathrm{~h}$ and $8.4 \times 10^{5} \mathrm{~h}$ of equivalent ageing time at $\left.323^{\circ} \mathrm{C}\right)$.

\begin{tabular}{lrrrr}
\hline $\begin{array}{l}\text { Ageing time } \\
\text { at } 350{ }^{\circ} \mathrm{C}(\mathrm{h})\end{array}$ & \multicolumn{1}{l}{2500} & 10,000 & \multicolumn{1}{c}{30,000} & 100,000 \\
\hline $\mathrm{Fe}$ & $54.3 \pm 2.2$ & $45.2 \pm 1.6$ & $40.5 \pm 0.6$ & $39.3 \pm 1.0$ \\
$\mathrm{Cr}$ & $15.5 \pm 1.8$ & $10.6 \pm 1.0$ & $10.5 \pm 0.4$ & $11.2 \pm 0.7$ \\
$\mathrm{Ni}$ & $16.6 \pm 3.0$ & $26.5 \pm 1.5$ & $26.9 \pm 0.6$ & $27.1 \pm 0.9$ \\
$\mathrm{Si}$ & $10.9 \pm 1.8$ & $12.5 \pm 1.1$ & $14.8 \pm 0.5$ & $15.8 \pm 0.7$ \\
$\mathrm{Mn}$ & $2.0 \pm 1.2$ & $4.4 \pm 0.7$ & $6.5 \pm 0.3$ & $5.7 \pm 0.5$ \\
$\mathrm{Mo}$ & $0.2 \pm 0.2$ & $0.2 \pm 0.2$ & $0.14 \pm 0.05$ & $0.17 \pm 0.08$ \\
\hline
\end{tabular}

give the first experimental confirmation that formation of the $\mathrm{G}$ phase particles proceeds at least via a two-step mechanism as suggested by Chung and Leax [5] and Mateo et al. [10]. The latters proposed that in a first stage, fluxes of G-forming species induced by their rejection from $\alpha$ and $\alpha^{\prime}$ domains lead to enrichment at the $\alpha / \alpha^{\prime}$ inter-domains in G-forming elements ( $\mathrm{Si}, \mathrm{Ni}, \mathrm{Mn}$ and $\mathrm{Mo}$ ). In a second stage, when the composition of the inter-domains reaches a critical composition, G-phase particles form. This two-step model appears coherent with the current measurements and observations. Nevertheless, it must be emphasized that APT does not give information on the crystallographic structure but only on composition. Consequently, we cannot be sure that the structure of the small particles observed is the one of the G-phase. Hence, it is not unlikely that the small G-forming enriched particles observed in the APT volumes are in fact precursors of G-phase particles and thus correspond to one more step on the ongoing process of Gphase particle formation. The only way to conclude on this point would be to be able to characterize the structure of these small precipitates by high resolution transmission electron microscopy (HRTEM) or TEM. But it is not quite that simple considering their small size and their probable coherency with the surrounding phases [31].

If one excludes this early stage of formation of G-phase particles and focuses on longer ageing times (i.e. from $10,000 \mathrm{~h}$ of ageing at $350{ }^{\circ} \mathrm{C}$ and $\sim 8.4 \times 10^{4} \mathrm{~h}$ at $323^{\circ} \mathrm{C}$ ), the effective time exponent of the time evolution of the $\mathrm{G}$-phase particle radius $(0.06)$ is equal to the one of $\lambda_{\alpha^{\prime}}$ (Figs. 3 and 4). Regarding the time evolution of number density and volume fraction of G-phase particles (Fig. 4c and b), two regimes are visible: firstly, simultaneous increase in number density and in volume fraction up to about $200,000 \mathrm{~h}$ in equivalent ageing time at $323^{\circ} \mathrm{C}$ ( or $30,000 \mathrm{~h}$ of ageing at $350{ }^{\circ} \mathrm{C}$ ), secondly, a decrease in number density whereas the volume fraction behaves asymptotically towards its equilibrium value which is about $1.6 \%$. These behaviours observed in the second regime are a signature of the coarsening regime of the G-phase particles.

\subsection{Comparison with Mo-bearing steels - discussion}

$\Delta \mathrm{C}_{\mathrm{Cr}}$ versus time plots for $\mathrm{A}$ and $\mathrm{B}$ Mo-bearing steels are given in Fig. 2 together with the plot obtained in steel E. Fig. 3 compares the evolution of $\lambda_{\alpha^{\prime}}$ for all Mo-bearing steels investigated together with the steel $\mathrm{E}$. These figures clearly show that spinodal decomposition is less developed in steel $\mathrm{E}$ than in Mo-bearing steels: both the amplitude of the decomposition and the effective time exponent of the wavelength are much lower in the steel $\mathrm{E}$.

The low time exponent for the steel $\mathrm{E}$ may not be assigned to the early time Cahn-Hilliard $(\mathrm{CH})$ linear regime for at least two reasons: i) if observed, this regime should only concern very early stages of ageing and not the overall kinetics as it is the case for steel E and ii) as reported in Refs. [26], the integrated intensity I(q) curves measured by SANS for steel E does not show any timeindependent intersection point, whereas it is expected by the $\mathrm{CH}$ linear theory or even by the Cahn-Hilliard-Cook ( $\mathrm{CHC}$ ) theory.

Three other possible explanations can be discussed.

- One explanation is the influence of homogenization temperature. Several works reported that the homogenization temperature may have strong influence on the evolution of the ferrite decomposition $[5,13,30]$. Nevertheless, as reported in Table 1 , the homogenisation temperature of steel $E$ is the same as of steels B, D and CE3 and close to the homogenization temperature of the others (difference is less than $50^{\circ} \mathrm{C}$ ). Moreover, according to Figs. 3 and 4, one can note that such a difference of less than $50{ }^{\circ} \mathrm{C}$ does not seem to have influence on the kinetics observed in the ferrite of Mo-bearing steels: one observes the 

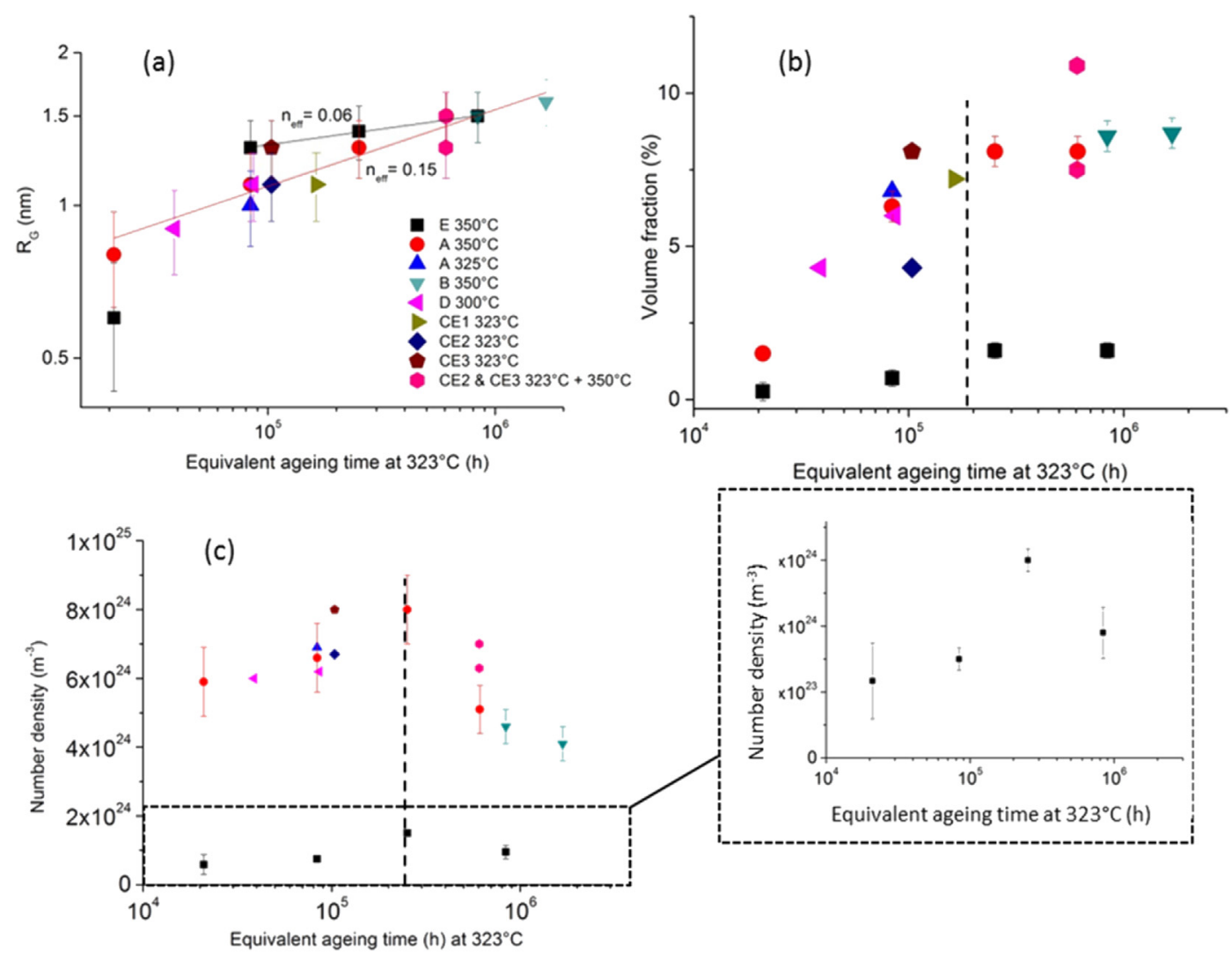

Fig. 4. Evolution of the radius (a), the volume fraction (b) and the number density (c) of G phase particles.

same time evolution of the wavelength, of the radius of $G$ phase particles and their number density.

- A second explanation is quench effects and related non-linear effects. Carmesin et al. [32] investigated the influence of quenching procedure on the initial stages of spinodal decomposition using simulation. By simulating quenching, they highlighted that there was no longer a unique intersection point for the structure function $\mathrm{S}(\mathrm{k})$ and that the shift of the maximum position of $\mathrm{S}(\mathrm{k})$ (i.e. the mean wavelength) depended only weakly on time. These simulated behaviours provide a good description of the behaviours observed in the present paper (Fig. 3). Confirmation of the existence of $\mathrm{Cr}$ heterogeneities after the quench (in the as-received state) in steel $\mathrm{E}$ was given by statistical tests using the method proposed by Thuvander et al. [33] performed on 3DAP volumes as reported in Fig. 5. The scurve represents the width of the frequency distribution of $\mathrm{Cr}$ atoms in the analysed volume and $\sigma$ the width of the binomial distribution corresponding to a random distribution of $\mathrm{Cr}$ atoms. The experimental s-curve is well above the binomial showing existence of $\mathrm{Cr}$ heterogeneities in the volume. Nevertheless, Fig. 5 also evidences the existence of similar $\mathrm{Cr}$ heterogeneities in steel A thus precluding any direct link between the heterogeneities observed after the quench and the low time exponent of the spinodal kinetics in steel E. Indeed, whereas heterogeneities exist in steel $\mathrm{A}$, a time exponent of 0.16 was observed.

- A third possible explanation are the Ni and Mo contents of the ferrite in steel E that differ from the Mo-bearing steels as reported in Table 3. The Ni and Mo concentrations are higher in ferrite of the Mo-bearing steels than in the Mo-free steel. Ni was shown to accelerate spinodal decomposition in $\mathrm{Fe}-\mathrm{Cr}-\mathrm{Ni}$ alloys $[2,13,34]$. Conversely, according to literature [11,14,15], Mo does not seem to play an important role for the kinetics evolution.
Indeed, the evolution of the Mo concentration in $\alpha$ zones, $\alpha^{\prime}$ zones and $G$ phase particles is not significant before at least $30,000 \mathrm{~h}$ of ageing at $350^{\circ} \mathrm{C}[11,14,15]$. Nevertheless, it cannot be ruled out that the Mo content influences the kinetics by modifying the width of the miscibility gap and then the driving force for $\alpha^{\prime}$ precipitation. Hayes et al.'s thermodynamic calculations [35] on the ternary $\mathrm{Fe}-\mathrm{Cr}-\mathrm{Ni}$ system showed that the driving force increases with $\mathrm{Ni}$ content for temperatures higher than

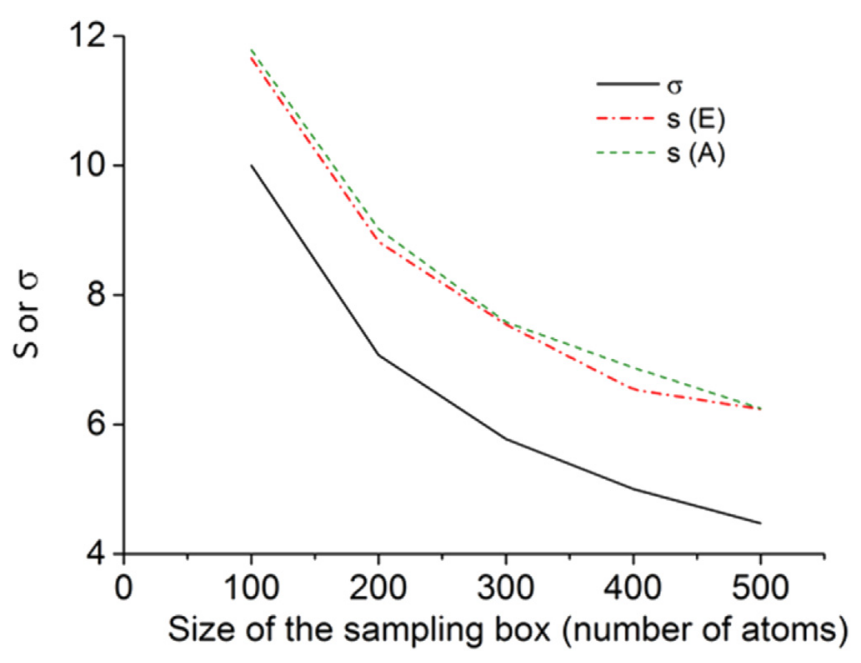

Fig. 5. Width (s-curve) of the frequency distribution of $\mathrm{Cr}$ atoms in ferrite of $\mathrm{A}$ and $\mathrm{E}$ as-received steels as function of the sampling size (number of atoms per sampling block). The width of the binomial distribution is displayed for comparison. The binomial distribution represents a random distribution of atoms. 
Table 3

Composition of the ferrite of steels A, B, D, CE1, CE2, CE3 (Mo-bearing) and E (Mo-free) (in at.\%).

\begin{tabular}{|c|c|c|c|c|c|c|c|}
\hline & A & B & $\mathrm{D}$ & CE1 & CE2 & CE3 & $\mathrm{E}$ \\
\hline $\mathrm{Fe}$ & $61.64 \pm 0.12$ & $60.81 \pm 0.12$ & $60.22 \pm 0.12$ & $61.78 \pm 0.11$ & $62.53 \pm 0.09$ & $63.53 \pm 0.31$ & $67.24 \pm 0.96$ \\
\hline $\mathrm{Cr}$ & $27.38 \pm 0.12$ & $27.51 \pm 0.11$ & $28.34 \pm 0.11$ & $27.33 \pm 0.10$ & $28.01 \pm 0.08$ & $25.91 \pm 0.29$ & $26.11 \pm 0.12$ \\
\hline $\mathrm{Ni}$ & $5.42 \pm 0.06$ & $5.48 \pm 0.06$ & $6.42 \pm 0.06$ & $5.61 \pm 0.05$ & $4.99 \pm 0.04$ & $5.98 \pm 0.16$ & $3.51 \pm 0.97$ \\
\hline $\mathrm{Si}$ & $2.59 \pm 0.04$ & $2.62 \pm 0.04$ & $2.46 \pm 0.04$ & $2.33 \pm 0.04$ & $1.57 \pm 0.02$ & $2.18 \pm 0.10$ & $2.56 \pm 0.02$ \\
\hline Mn & $0.54 \pm 0.02$ & $0.70 \pm 0.02$ & $0.45 \pm 0.02$ & $0.58 \pm 0.02$ & $0.66 \pm 0.02$ & $0.37 \pm 0.04$ & $0.21 \pm 0.01$ \\
\hline Mo & $2.09 \pm 0.04$ & $2.57 \pm 0.04$ & $1.88 \pm 0.03$ & $2.03 \pm 0.03$ & $2.07 \pm 0.03$ & $1.89 \pm 0.09$ & $0.03 \pm 0.01$ \\
\hline C & N.M. ${ }^{-}$ & $0.02 \pm 0.01$ & N.M. $^{a-}$ & N.M. ${ }^{-}$ & N.M. ${ }^{-}$ & N.M. ${ }^{a-}$ & $0.01 \pm 0.01$ \\
\hline
\end{tabular}

a N.M.: No measurable.

$300{ }^{\circ} \mathrm{C}$ in the $\mathrm{Ni}$ concentration range of interest. But in this respect, it is worth noting that the driving force is not expected to modify the effective time exponent but rather the time constant $\mathrm{A}$ of the relationship $\mathrm{At}^{\mathrm{n}}$. Indeed, the effective time exponent of a phase transformation is strongly related to the diffusion mechanism. As explained by Huse [36], the effective time exponent of the evolution of the domain size of an interconnected structure must evolve gradually with time, depending on the relative weight of interface diffusion and bulk diffusion. At short ageing times, when vacancy diffusion proceeds mainly along the interfaces, the effective time exponent is small. Afterwards, it increases and tends progressively towards $1 / 3$ when bulk diffusion becomes dominant [36]. This is the reason why effective time exponents between 0.16 and 0.24 are reported in the literature. They correspond to different stages of the kinetics of the interconnected structure, i.e. different relative weight of interface and bulk diffusion. This was evidenced in $\mathrm{Fe}-\mathrm{Cr}$ system by Ujihara and Osamura [37] and by atomistic kinetic Monte Carlo simulations on rigid lattice by Pareige et al. [8] in $\mathrm{Fe}-\mathrm{Cr}$ and in a ternary system $\mathrm{A}-\mathrm{B}-\mathrm{C}$ (where A stands for $\mathrm{Fe}, \mathrm{B}$ for $\mathrm{Cr}$ and $\mathrm{C}$ for $\mathrm{G}$-forming elements) [38]. The fact that no evolution of the effective time exponent is observed neither in Mo-bearing nor in Mo-free steels, indicates that diffusion should mainly proceeds via interface diffusion even after $200,000 \mathrm{~h}$ of ageing at $350{ }^{\circ} \mathrm{C}$. The low exponent in steel $\mathrm{E}$ could therefore be due to a higher relative weight of interface diffusion with respect to bulk diffusion. Another diffusion mechanism leading to the slowing down of the kinetics that could be considered is a mechanism involving the diffusion of $\mathrm{n}$-mers (small clusters) instead of monomers [28,39].

Whatever the mechanism at the origin of the slowing down of the kinetics, this would mean that Ni and/or Mo modify the diffusion mechanism. But in that case, why are the diffusion mechanism and the associated time exponent similar in both Mo-bearing steels with high $\mathrm{Ni}$ and Mo contents and binary $\mathrm{Fe}-\mathrm{Cr}[30,40]$ with no Ni and Mo, whereas they differ in the ferrite of Mo-free steel which contain less $\mathrm{Ni}$ and Mo? If the diffusion mechanisms are really at the origin of the different time exponents, one still has to understand why these different mechanisms take place in Mo-bearing and the steel $\mathrm{E}$. The question is under investigation.

Quantitative data related to the characterisation of the G-phase particles in Mo-bearing steels are given in Fig. 4 together with data from the Mo-free steel. For both steel families, the G-phase particle radius evolves with the same effective time exponent as the wavelength: 0.15 in Mo-bearing and 0.06 in Mo-free. This was already reported for Mo-bearing grades $[7,14]$ but not for Mo-free. The kinetic synergy between spinodal decomposition and Gphase precipitation also exists in Mo-free DSS. Regarding the intensity of the G-phase precipitation, as expected, the intensity of precipitation is much less in the Mo-free DSS than in the Mobearing steels which contain much more G-forming elements.
The ratio between the number density in Mo-bearing steels and steel $\mathrm{E}$ varies from 5 to 9 . Such differences have already been reported in literature for similar steels $[1,7,9]$. But despite this difference, it is noticeable that for both Mo-free and Mo-bearing grades, the coarsening regime starts after similar ageing time i.e. about $200,000 \mathrm{~h}$ in equivalent ageing time at $323^{\circ} \mathrm{C}$ ( or $30,000 \mathrm{~h}$ of ageing at $\left.350{ }^{\circ} \mathrm{C}\right)$. Moreover, in both cases, the effective time exponent of the evolution of the G-phase particle radius does not evolve to tend towards $1 / 3$ as expected during coarsening. This originates from the diffusion mechanism involved during coarsening as we showed by kinetic Monte Carlo simulation [38]. In the simulations, the kinetics was simulated using a simple but effective atomic kinetic Monte Carlo model in a ternary alloy $\mathrm{Fe}-\mathrm{Cr}$-X where $\mathrm{X}$ stands for $\mathrm{G}$-forming elements. The simulations reproduced the kinetics observed in ferrite of Mo-bearing steels. By following the vacancy pathway, the synergy between G-phase precipitation and spinodal decomposition was explained. We showed that coarsening of particles proceeded via diffusion of atoms along the interfaces explaining the non-evolution of the time exponent during coarsening but also the non-evolution of the time exponent for long ageing time for spinodal decomposition. The results obtained in the E Mo-free steel show the same behaviour for G-phase particles but with a much lower number density.

\section{Conclusions}

In this paper, the evolution of phase transformations (spinodal decomposition and G-phase precipitation) in ferrite of a thermally aged Mo-free duplex stainless steel was studied and characterised by APT. The results were compared to the evolution observed in ferrite of some Mo-bearing steels aged in similar conditions. This paper showed that:

- Phase transformation in ferrite starts firstly by $\alpha / \alpha^{\prime}$ spinodal decomposition and that G-phase precipitate formation at the $\alpha /$ $\alpha^{\prime}$ interface results in the rejection of G-forming species from the $\alpha$ and $\alpha^{\prime}$ domains. The results give experimental evidence that the formation of the G-phase particles proceeds at least via a two-step mechanism: G-forming enrichment at $\alpha / \alpha^{\prime}$ interdomains followed by formation of G-phase particles when a critical composition (and perhaps size) is reached. But as APT does not give access to the crystallographic structure, it is not unlikely that the small G-forming enriched particles observed in the APT volumes are in fact precursors of G-phase particles and thus correspond to one more step on the ongoing process of $G$ phase particle formation.

- As expected, the intensity of the G-phase precipitation is much less in the Mo-free DSS than in Mo-bearing steels which contain much more G-forming elements. The kinetic synergy observed in Mo-bearing steels between spinodal decomposition and Gphase precipitation was shown to also exist in Mo-free DSS. Moreover, for both Mo-free and Mo-bearing grades the 
coarsening regime starts after similar ageing time, i.e. about $200,000 \mathrm{~h}$ in equivalent ageing time at $323^{\circ} \mathrm{C}$ (or $30,000 \mathrm{~h}$ of ageing at $350{ }^{\circ} \mathrm{C}$ ).

- Spinodal decomposition is less developed in Mo-free steel than in Mo-bearing steels: both the amplitude of decomposition and the effective time exponent of the wavelength ( 0.06 versus 0.16 ) are much lower in the ferrite of the Mo-free steel. Investigation of the kinetics in other Mo-free steels is mandatory to know if the behaviour observed in the steel $\mathrm{E}$ is representative of all Mofree steels or not. Neither the temperature of homogenisation nor quench effects or $\mathrm{Ni}$ and Mo contents could successfully explain the low time exponent of the spinodal decomposition observed in the Mo-free steel. The diffusion mechanisms could be at the origin of the different time exponents (diffusion along $\alpha / \alpha^{\prime}$ interfaces or n-mers diffusion). Nevertheless, one still has to understand why different mechanisms (if they really exist) could take place in Mo-bearing and the E steel. The question is under investigation.

\section{Acknowledgements}

This work was supported by the Upper Normandy Region and the French Ministry of Research in the framework of Research Networks of Upper Normandy (GRR Energie, Electronique, Matériaux). This work is a part of the research program of the EDFCNRS joint laboratory EM2VM (Study and Modeling of the Microstructure for Ageing of Materials).

\section{References}

[1] P. Auger, F. Danoix, A. Menand, S. Bonnet, J. Bourgoin, M. Guttmann, Mater. Sci. Technol. 6 (1990) 301.

[2] H.D. Solomon, L.M. Levinson, Acta Metall. 26 (1978) 429.

[3] A. Trautwein, W. Gysel, Int. Cast. Met. J. 6 (1981) 43.

[4] S. Bonnet, J. Bourgoin, J. Champredonde, D. Guttmann, M. Guttmann, Mater. Sci. Technol. 6 (1990) 221.

[5] H.M. Chung, T.R. Leax, Mater. Sci. Technol. 6 (1990) 249.

[6] J.J. Shiao, C.H. Tsai, J.J. Kai, J.H. Huang, J. Nucl. Mater. 217 (1994) 269.

[7] F. Danoix, P. Auger, Mater. Charact. 44 (2000) 177.

[8] C. Pareige, M. Roussel, S. Novy, V. Kuksenko, P. Olsson, C. Domain, P. Pareige,
Acta Mater. 59 (2011) 2404.

[9] M.K. Miller, J. Bentley, Mater. Sci. Technol. 6 (1990) 285.

[10] A. Mateo, L. Llanes, M. Anglada, A. Redjaimia, G. Metauer, J. Mater. Sci. 32 (1997) 4533.

[11] F. Danoix, P. Auger, D. Blavette, Surf. Sci. 266 (1992) 364.

[12] F. Danoix, B. Deconihout, A. Bostel, P. Auger, Surf. Sci. 266 (1992) 409.

[13] J.E. Brown, G.D.W. Smith, Surf. Sci. 246 (1991) 285.

[14] C. Pareige, S. Novy, S. Saillet, P. Pareige, J. Nucl. Mater. 411 (2011) 90.

[15] S. Novy, Mécanisme de Vieillissement À Très Longue Échéance Des Aciers Inoxydables Austénoferritiques, PhD, University of Rouen, France, 2009.

[16] J. Brown, An Atom Probe Study of the Spinodal Decomposition in $\mathrm{Fe}-\mathrm{Cr}-\mathrm{Ni}$, PhD, University of Oxford, Oxford, UK, 1990.

[17] T. Leax, S.S. Brenner, J.A. Spitznagel, Met. Trans. 23A (1992) 2725.

[18] Da Costa, F. Vurpillot, A. Bostel, M. Bouet, B. Deconihout, Rev. Sci. Instrum. 76 (2005) 13304.

[19] E. Bémont, A. Bostel, M. Bouet, G. Da Costa, S. Chambreland, B. Deconihout, K. Hono, Ultramicroscopy 95 (2003) 231.

[20] D. Blavette, A. Bostel, J.M. Sarrau, B. Deconihout, A. Menand, Nature 363 (1993) 432.

[21] D. Blavette, B. Deconihout, A. Bostel, J.M. Sarrau, M. Bouet, A. Menand, Rev. Sci. Instrum. 64 (1993) 2911.

[22] M.K. Miller, Atom Probe Tomography: Analysis at the Atomic Level, Kluwer Academic/Plenum Publishers, 2000.

[23] M.G. Hetherington, M.K. Miller, J. Phys. Colloq. 50 (1989) C8.

[24] J. Zhou, J. Odqvist, M. Thuvander, P. Hedström, Microsc. Microanal. 19 (2013) 665.

[25] C. Pareige, V. Kuksenko, P. Pareige, J. Nucl. Mater. 456 (2015) 471.

[26] J. Emo, Etude Expérimentale et Par Simulation Monte Carlo Des Transformations de Phase Dans La Ferrite Des Aciers Austéno-Ferritiques et de Leurs Alliages Modèles, PhD, University of Rouen, France, 2014.

[27] J. Langer, M. Bar-on, H. Miller, Phys. Rev. A 11 (1975) 1417.

[28] K. Binder, D. Stauffer, Phys. Rev. Lett. 33 (1974) 1006.

[29] T. Hamaoka, A. Nomoto, K. Nishida, K. Dohi, N. Soneda, Philos. Mag. 92 (2012) 4354.

[30] J.C. Lasalle, L.H. Schwartz, Acta Met. 34 (1986) 989.

[31] T. Hamaoka, A. Nomoto, K. Nishida, K. Dohi, N. Soneda, Philos. Mag. 92 (2012) 2716.

[32] H. Carmesin, D. Heermann, K. Binder, Z. Phys. B-Condens. Matter 65 (1986) 89.

[33] M. Thuvander, H.O. Andren, K. Stiller, Q.H. Hu, Ultramicroscopy 73 (1998) 279.

[34] P. Hedström, F. Huyan, J. Zhou, S. Wessman, M. Thuvander, J. Odqvist, Mater. Sci. Eng. A 574 (2013) 123.

[35] F. Hayes, M.G. Hetherington, R. Longbottom, Mater. Sci. Technol. 6 (1990) 263.

[36] D.A. Huse, Phys. Rev. B 34 (1986) 7845.

[37] T. Ujihara, K. Osamura, Acta Mater. 48 (2000) 1629.

[38] J. Emo, C. Pareige, S. Saillet, C. Domain, P. Pareige, J. Nucl. Mater. 451 (2014) 361.

[39] M. Athènes, P. Bellon, G. Martin, Acta Mater. 48 (2000) 2675.

[40] F. Bley, Acta Met. Mater. 40 (1992) 1505. 